\title{
Kiyang-yang, a West-African Postwar Idiom of Distress
}

\author{
Joop T. de Jong $\cdot$ Ria Reis
}

Published online: 27 April 2010

(C) The Author(s) 2010. This article is published with open access at Springerlink.com

\begin{abstract}
In 1984, a healing cult for young barren women in southern Guinea Bissau developed into a movement, Kiyang-yang, that shook society to its foundations and had national repercussions. "Idiom of distress" is used here as a heuristic tool to understand how Kiyang-yang was able to link war and post-warrelated traumatic stress and suffering on both individual and group levels. An individual experience born from a traumatic origin may be generalized into an idiom that diverse sectors of society could embrace for a range of related reasons. We argue that, for an idiom to be understood and appropriated by others, there has to be resonance at the level of symbolic language and shared experiences as well as at the level of the culturally mediated contingent emotions it communicates. We also argue that through its symbolic references to structural causes of suffering, an idiom of distress entails a danger for those in power. It can continue to exist only if its etiology is not exposed or the social suffering it articulates is not eliminated. We finally argue that idioms of distress are not to be understood as discrete diagnostic categories or as monodimensional expressions of "trauma" that can be addressed.
\end{abstract}

\footnotetext{
J. T. de Jong ( ()

Department of Cultural and International Psychiatry, VU University Medical Center,

De Boelelaan 1105, 1081 HV Amsterdam, The Netherlands

e-mail: jtvmdejong@gmail.com

J. T. de Jong

Department of Psychiatry, Boston University School of Medicine, Boston, MA, USA

R. Reis

Amsterdam Master's in Medical Anthropology, Amsterdam School of Social Science Research, University of Amsterdam, Amsterdam, The Netherlands

R. Reis

Leiden University Medical Center, Leiden, The Netherlands
} 
Keywords Idiom of distress - Healing cult - Dissociation - Traumatic stress · Social suffering - Central possession religion - Clairvoyance · Guinea Bissau . Kiyang-yang $\cdot$ Barrenness $\cdot$ Witchcraft $\cdot$ Political violence $\cdot$ Armed conflict

\section{Introduction}

Idioms of distress generally refer to culturally specific expressions of suffering or, following Nichter (1981; cf. Sargent 2003), to alternative modes of expressing and communicating distress that make sense and invite action within the context of specific complexes of personal and cultural meaning. Hollan's (2004) definition more explicitly refers to the metaphorical dimension. According to Hollan (2004, p. 63), an idiom of distress refers to shared, culturally distributed sets of symbols, behaviors, language or meanings that are used by people to express, explain and/or transform their distress and suffering. It is this symbolic dimension that makes it appropriate to speak of an idiom because an idiom employs or enacts language where straightforward language does not suffice or is not allowed. Typically, an idiom of distress uses a shared language in which the signs do not unambiguously convey specific meanings (Nichter 1981, p. 401; Furst 2003; cf. Reis 2009).

There are two problems with the use of the concept in current anthropological, psychological and psychiatric discourse, both of which cloud its heuristic value. One is that idioms of distress are, at times, described not as a particular means for expressing distress, but as a type of distress, so that cultural idioms of distress mistakenly become a label for illnesses that are considered culture-bound-that is, for discrete diagnostic categories (Ensink and Robertson 1996, p. 162; cf. Davis and Joakimsen 1997). In our view, the second problem, which was already apparent in Nichter's original article, is that the meaning of the concept becomes stretched to the extent that any culturally influenced experience and expression of distress will be denominated as a cultural idiom of distress. This, as Kirmayer (1989) observes, includes virtually every human experience and expression of distress per se. To enhance the heuristic value of the concept, we prefer a more restricted use. We define an idiom of distress as an embodied symbolic language for psychosocial suffering that derives its legitimacy from its shared metaphors, meaning and understanding in a group. Additionally, its multilevel and multi-interpretable nature and its use of condensed symbols allow the individual to express and communicate suffering caused by different types of stressors that cannot otherwise be expressed in the local social-cultural-political context, due to the inherent threat such expression would constitute to culturally dominant values and structures.

Most studies that use idioms of distress as an analytic tool describe already existing idioms in which people can express their distress. We are in a unique position, in that 26 years ago, one of us (J.d.J.) witnessed the inception of a presentday West African idiom of distress, the Kiyang-yang in Guinea Bissau, and even played a modest role in its continuation.

In the autumn of 1984, a wave of rumors spread across southern Guinea Bissau about "mad" Balanta women who were unable to conceive or whose children had 
died. They tried to find relief from a woman who received messages from the Balanta god Nhaala, telling her to cure other people, pointing out medicinal herbs and commanding her to put an end to witchcraft in the country. What started as a healing cult for individuals developed into a movement of young people, especially women, that shook Balanta society to its foundations and had national repercussions. At the time, the first author worked as a psychiatrist in the country (from 1981 till 1985). "The state authorities sent him to the south to treat the "crazy women." He transformed this order into ethnographic research and, subsequently, tried to convince the government not to medicalize a collective dissociative phenomenon that, in his opinion, was caused by massive traumatic stress. To a large extent, the stress was caused by 22 years of liberation struggle that had ended in 1974. It had escalated into bombardments with napalm and the widespread use of landmines, resulting in large numbers of casualties, amputations and refugees. Part of the population chose to live in the liberated areas, whereas the Portuguese copied the Algerian and Indochinese policy of "protected villages," obliging the local population to function as a shield against attacks of the guerrilla movement. The war caused further deterioration in the already primitive public health and educational structures that had thus far resulted in only $0.3 \%$ of the population qualifying as literate and "civilized." This war of independence became successful due to the dominant role of the Balanta, who carried the brunt of the traumatic burden in terms of personal and communal losses (de Jong and Buijtenhuijs 1979). De Jong's interpretations focused on the sociopolitical meanings of Kiyang-yang. He interpreted Kiyang-yang as a collective coping strategy for dealing with stressors originating in three fields of social change: the precarious socioeconomic position of the Balanta as an ethnic group within the newly formed state of Guinea Bissau, the position of Balanta women in relation to gender hierarchies, and postwar intergenerational tensions (de Jong 1987). This sociopolitical analysis agreed with previous analyses of social movements in religious anthropology that generally focused on a collective level, such as antiwitchcraft movements or collective possession (Richards 1935; Marwick 1950; Willis 1968; Ranger 1986; cf. Geschiere 1998; van Dijk et al. 2000; Lewis 2003 [1971]).

Building on this previous work, in this paper we use the concept "idiom of distress" to revisit the phenomenon. We describe how an individual experience born from a traumatic origin could develop into a possession and healing cult for marginalized, barren women. We then discuss how it generalized into an idiom that allowed the expression of a variety of individual and collective stressors, which exposed structural tensions of the Balanta in a postwar society. Our aim is to understand how Kiyang-yang was able to link traumatic stress and social suffering on both individual and group levels. In addition, we describe those processes that helped to impede its development into a political movement and into a central possession religion, thus preserving it as an idiom of distress up to this day.

\footnotetext{
1 Joop de Jong first worked in Guinea Bissau from 1974 until 1975, in tropical medicine and public health during and after the liberation struggle. At the request of the Guinean government, he returned to the country after his specialization in psychiatry and psychotherapy.
} 
The structure of this paper is as follows. After a brief introduction to Guinea Bissau, a historical description will show how the movement started with the individual suffering of its leader Ntombikte and her calling by the Balanta god Nhaala, which was followed by a further calling to service of some female family members and of a larger group of women and men. We then describe the period of repression by the state and the evolution of the Kiyang-yang over time, allowing the idiom to become a medium of expression of related but ever widening social suffering. In the discussion, we briefly describe some parallels with a pre-existing cult that has also intervened in times of epidemic disease and misfortune. We then discuss how individual suffering was connected to collective suffering by the commandments of the Balanta god. We show how individual suffering may create a political danger if it becomes a metaphor of collective suffering due to structural poverty and violence. We argue that the idiom of distress can only continue to exist if its etiology is neither exposed nor solved.

\section{Guinea Bissau}

The Republic of Guinea Bissau is wedged between Senegal to the north and the Republic of Guinea to the east and south. The territory is between the size of Belgium and that of Switzerland and can be roughly divided into a coastal area with mangrove forests, the interior with savannah and the south with forests. The estimated population is 1,100,000 (1996 census). The major ethnic groups are the Balanta (27\%), the Fula (23\%), the Mandinga (12\%), the Manjac (10\%) and the Papel (10\%). About half of the population follows an ancestral religion, $40 \%$ is Muslim and a small percentage is Christian. A Guinean Crioulo, similar to the Papiamento of the Dutch Antilles, is spoken by almost half of the population. After the abolition of slave trade, the mainland was neglected by the Portuguese, who saw little value in the swampy and disease-ridden colony. Only after the 1886 agreement with France did the Portuguese start their "pacification campaign," which was accompanied by bloody battles that continued until the 1930s.

In 1956, Amilcar Cabral founded the Partido Africano da Independência da Guiné e Cabo Verde (PAIGC). After a massacre in the Bissau harbor in 1959, the PAIGC launched an armed struggle against the Portuguese in 1962. After 2 years of fighting, more than two-thirds of the country was liberated. In 1973, Amilcar Cabral was murdered, and in autumn of that year, the PAIGC proclaimed independence under the leadership of Amilcar's half-brother Luiz Cabral. Independence was recognized by the Portuguese in September 1974, five months after the April 1974 revolution in Lisbon, marking the end of Portuguese colonialism. The International Crisis Group states that "since 1974, Guinea-Bissau has experienced a recurrent cycle of political crises and coups d'état, while criminal networks have proliferated." On November 14, 1980, the Prime Minister Vieira, from the Papel ethnic group, led a coup in which the Cabral regime was overthrown. A group of military, mainly Balanta, had prepared the coup and asked the Papel Vieira to become president because of his charisma as a PAIGC commander. The Balanta were content with the nomination of a Balanta, Paulo Correia, as vice president (de Jong 
and Buijtenhuijs 1979; de Jong 1987). Further on we will see which role these dramatis personae play in the Kiyang-yang movement. In 2009, President Vieira was murdered in reprisal for a bomb attack that had killed the army chief of staff the night before (New York Times, March 2, 2009).

Despite a newly installed multiparty democratic system, since independence the economy of the country has gradually declined, with cashew exports and fishing rights as the main state revenue. Guinea Bissau ranked 173 of 182 countries on the Human Development Index in 2007.

The number of risk factors for armed conflict gradually increased (de Jong 2010): poverty, corruption, disappearances, uneven economic development, narcotics trafficking and a decline in public services, to mention only a few. In June 1998, a civil war broke out. The capital city of Bissau was the main fighting zone, and the city's 300,000 inhabitants fled rapidly to the interior of the country when the war started. When a cease-fire agreement was reached one month later, the city's population returned slowly, only to flee again during renewed fighting in October 1998 and February 1999 (Gustafson et al. 2001).

In summary, in past decades Guinea Bissau was affected by multiple episodes of political violence that created a huge amount of human suffering caused by war, bombardments, waves of refugees and internally displaced persons, deprivation and poverty, the decline of social safety nets, availability of weapons, mutilation by landmine and UXO accidents, high rates of (infant) mortality, unemployment, human rights violation, ethnic tensions and criminalization of the state. Whereas this burden is an unfortunate universal phenomenon inherent to political violence, one of the local sources of resilience seems to be unique, as the Kiyang-yang movement illustrates.

\section{Ntombikte's Initiatory Illness and Calling by the Balanta God Nhaala}

The founder of the movement was about 35 years old when she was called in July 1984. Before her calling, she had suffered high levels of distress as a result of the traumatic war events described above. Moreover, she had lost several children to disease. During our visits to Ntombikte, it became clear that she suffered from prolonged periods of despair and depressed moods. Apart from the emotional burden caused by the loss of a child per se (cf. Einarsdóttir 2004; de Jong 2007), a bereaved mother may be stigmatized by her family or covillagers. Like barren women, she fails to produce what the family expects: children who will till the land and who are the family's means of production. Without children, she will not find a place in the reincarnation cycle of the ancestral spirits. Additionally, among the Balanta, the death of a child can be attributed to witchcraft, which may involve the mother, her family or the village. In this context, a bereaved mother endures unbearable distress. She may have to suspect others close to her of having harmed her child, but she may also silently or openly be accused of the death of her own child while she is grieving her loss.

Ntombikte told us that she visited several oracles before her calling but that she did not succeed in discovering the cause of her illness. Being exposed to the existential uncertainty caused by the Balanta belief in witchcraft, Ntombikte took an 
exceptional decision to escape possible evildoers in her husband's family: she left the compound of her family-in-law, whom she regarded as possibly infested with witchcraft, and founded her own independent compound. This was extraordinary behavior among the Balanta, where a woman would normally return to her own family or chose to live with another man in his compound. Soon after this decision, she was called by the Balanta god Nhaala:

During the rice-planting season of 1983, I became ill. I was unable to discover the cause of my illness. A year later, I lost my only surviving child. Within one month afterward, I started to feel pain all over my body. One afternoon, I suddenly jumped up from my stool, ran around, and did not know what was happening to me. My head was shaking and my body was thrown to all sides. While I was running around Nhaala opened my mouth and made me announce that he was calling me. I had a dream that a white man in a white robe visited me. He handed me a book like your writing pad, and a pen and taught me how to write. Then it also became clear to me that my strange sickness came from Nhaala, god. I soon realised that I should follow him. He guided me and gave me orders. He taught me and forced me to speak. He told me that the Balanta should get rid of their [ancestor] spirits and ancestor shrines. The people should not hold their big mourning feasts any more slaughtering their whole herd of cattle. They were to stop stealing and stop beating the great slit drum during mourning feasts to praise or mock the cattle-stealing achievements of the guests. I also had to tell people that they were to refrain from witchcraft, not to eat pork and not to drink alcohol, and that they should work hard instead. In a dream, Nhaala told me to change my name to Kiyang-yang. About once or twice a day god forced me to rush around until I knelt down in a clearing pointed out by him. Then he guided my hand, in which I was holding a digging-knife, and made me dig a hole. There I found a root, the healing properties of which were explained to me by god.

The orders of god came to her in the form of an experience, which she described as follows: "God gives me his orders by means of voices which I hear in my head. Usually, it is the voice of my father's younger brother, who died during the liberation struggle and whom I took care of before his death." God could also enter her body, which turned hot when she had visions:

Mostly it happens when I lie in bed before I fall asleep, and sometimes during the day or in a dream. It is like a cinema, I see colored moving pictures which come and go and which show the way of Nhaala. These orders are more important than the voices, and if I don't accept them, my body hurts and I feel as somebody who is very ill and who may die. If I accept, my body feels fine. But I can't see god's face. Sometimes when I see the pictures, he sits down in a long white garment that covers his face. Nhaala can also give me an order just like that, for instance the way we sit here, he may tell me to stand up and clean the whole place.

As I told you, Nhaala ordered me to change my name given by my father when I was born, Ntombikte ["I went there to see" in Balanta], into Kiyang-yang ["the shadow"]. 
Later on Ntombikte — or, in her opinion, Nhaala_changed her name to Maria or Mariama, names with Christian and Muslim connotations, respectively. Nhaala forced Ntombikte to move around and to pass his commandments as well as laws to the people and to search for medicinal roots. With the aid of a potion that Ntombikte prepared from these roots, she became pregnant and gave birth to a son who survived.

\section{From Individual Suffering to a Cult for Marginalized Barren Women}

A few months after Ntombikte's calling, 40 other young women and a few young men were called by Nhaala. Their calling was very similar to that of Ntombikte. They joined Ntombikte and moved into her compound. Ntombikte started her healing practices at the behest of Nhaala. She treated her followers as well as people from the surrounding area who came to her compound with some sickness or other misfortune. Her divinatory powers enabled her to diagnose the cause of the complaint, after which she prescribed a medicine or referred the patients to one of her followers. Most of the followers themselves were still undergoing treatment. In addition, they had some specialized skill, usually connected with the type of roots that they dug up, the healing properties of which either Ntombikte or god himself had taught them. In many cases, their specialization was related to the complaint from which they themselves suffered when they were called.

During ethnographic fieldwork in 1984 and 1985, the first author interviewed 16 followers of Ntombikte, who already in that period were referred to as Kiyang-yang by both Balanta and non-Balanta. The selection was based on a convenience sample in the south and in the capital, Bissau; the interviews were semistructured and indepth. The respondents lived in a variety of locations for which a census showed that, on average, $12 \%$ of the population was called by the Balanta god Nhaala. ${ }^{2}$ Based on these interviews and on participant observation, one can follow the gradual development of a new idiom of distress, its behavioral, personal and social concomitants and the evolution of a movement.

The female followers in our sample were aged between 20 and 25 on average. The men tended to be a little younger. There were a few exceptions, with extremes of 7-60 years of age. The ratio of women to men was four to one. About 15 women were undergoing treatment for one of the most stigmatizing misfortunes that can befall an African woman, i.e., barrenness. For these Guinean women, Ntombikte was a last resort after an endless trek from one healer and hospital to the next. Ten of these followers had lost all their children. Several others suffered from complaints such as stomachache or epileptic or psychogenic non-epileptic seizures. Later on, some female relatives of Ntombikte were also called and, after instruction by Ntombikte, rapidly gathered a following. ${ }^{3}$

\footnotetext{
2 On the basis of a government census that had just been conducted and on our own counts (J.d.J.), both in 1985, we arrived at the following percentages of adult women who were members of Kiyang-yang in the following villages: Cantonas, 7.5\%; Orango, 18\%; Dju de Infanda, 6\%; Uncomene, 10\%; Mato Farroba, 10\%; Cobumba, 13.5\%; and Quitafine, $23 \%$.

3 Biiba, her half-sister, Buini, a daughter of Ntombikte's brother, and Biankeia, the daughter of a cousin of Ntombikte. Their calling took place in January and February 1985.
} 
The interviewees claimed that those who were called had no control whatsoever over their calling or their behavior. Many said they wanted to be called, but few were chosen. Several followers were embarrassed by their calling because they did not believe in Kiyang-yang or because they were afraid of losing their jobs. Seven of the sixteen Kiyang-yang informed us that they had had a dream or vision in the month preceding their calling. In their dream, they saw an old man with a white face, long white hair and a long white robe. Five informants told us that this dream occurred in a period during which they ate and drank nothing for 5-15 days. ${ }^{4}$ All interviewees narrated that on a random day, during the daytime or at night, they felt a strange sensation in their heads and bodies. Their heads felt light, and in some cases, this was accompanied by respiratory difficulties, a buzzing sound in the ears, heart palpitations or rapid thoughts. Their bodies felt heavy, as in drunkenness. Some felt that their bodies trembled and became cold or that their legs suddenly felt light. Then their bodies, arms or legs started to shake, and they had to run, during which they lost all sense of direction and often sustained injuries on their feet and lower legs. This running-around was a highly consistent characteristic of the calling. Several Kiyang-yang told that they did crazy things like taking all their clothes off, climbing onto the rafters of the huts or swimming across a mangrove river arm with crocodiles. Until June 1985, about one year after Ntombikte's calling, when the movement was still restricted to the south, the Kiyang-yang ran to Ntombikte's house, throwing themselves at her feet, while their heads made short, jerky movements frontward and backward. After half a day, or sometimes longer, they started talking about their inability to conceive, about their children who had died or about their calling by god. Some of them confessed all their sins, with gossip, theft and adultery featuring prominently among them. Ntombikte then looked to see if the calling was authentic. If she saw that the recently called woman was a witch, she sent her back home without further comment. Those who did not understand what happened were reassured and told that god had come into them. After staying a few days in Ntombikte's compound or with nearby acquaintances, the new Kiyang-yang were sent once or twice a day, by the same invisible force of god, into the bush with several other followers to dig up medicinal roots. The period of running around could range from a few days to a month, according to the interviews. Most of the Kiyang-yang indicated a partial or total amnesia during the period of running.

After a few days up to a month, or sometimes even three months, the signs of the calling phase receded. Subsequently, the Kiyang-yang heard voices transmitting messages and orders from the highest being, Nhaala. These voices were heard inside the head. In some cases, they were accompanied by glossolalia, with the voices loosening the tongue of the Kiyang-yang, thus compelling them to announce god's message. Hearing the voices was accompanied by strange behavior, which varied from one individual to the next, and could range from convulsive movements of the

\footnotetext{
${ }^{4}$ In two cases, this fasting was accompanied by what an etic psychological view would describe as a major depressive episode with melancholia. Fasting often occurs in the calling of healers and in shamanistic tradition. Compare the fasting of Jesus in the desert.
} 
head, body and limbs to the uttering of strange human or animal sounds. The voices were attributed to deceased parents or grandparents who had a positive bond with the afflicted person. ${ }^{5}$ Most often, two voices were heard, although in exceptional cases three or four might be heard. Usually the Kiyang-yang could tell straight away to whom the voices belonged. When this question was put to them, some proceeded to ask their voices, whereupon their bodies started shaking, or they waved their arms or spun around because the voice was not always prepared to disclose its identity at that particular moment. In both female and male followers, the majority of the voices were male-sounding. The voices communicated in either Balanta or Crioulo, the lingua franca of the country, or Portuguese or an entirely new language that no one had heard before and that could be understood only by followers who had undergone Ntombikte's purification ceremony. The messages from Nhaala were transmitted exclusively through the voices (Ntombikte was an exception). Clairaudience was attributed to the voices because a voice might tell whether someone was a witch or whether an illness was due to witchcraft, or the voice might indicate that an illness was located in a particular part of the body. In addition, the followers became clairvoyant and clairolfactive. This special sense of smell served for tracking down the evil smell of witches and witchcraft.

After some weeks or months, the voices would quiet down. Their interventions became less frequent and concentrated on diagnosing sickness and witchcraft or punishing a follower when she did not adhere to the rules of god. All the followers tried to undergo Ntombikte's purification ceremony to become Kiyang-yang. After the ceremony, she could operate independently as a healer and understand the new language that only Kiyang-yangs were believed to understand among themselves. She was then also capable of 'recording' that language in the handwriting of the Kiyang-yangs, which differed from one individual to the next. ${ }^{6}$ The Kiyang-yangs claimed that they did remember all events that took place, including the reasons why their voices chastised them and the way in which that happened.

\section{Emerging Rules}

During our fieldwork, we observed that Ntombikte indicated new codes of behavior, which had been given to her by god and which the people could follow if they wished. In the first years, she never acted like a preacher, nor did she attempt to impose the code of behavior on others. ${ }^{7}$ In contrast with Ntombikte's behavioral

\footnotetext{
5 In order of frequency they were as follows: the voice of the biological father, that of the paternal grandfather and grandmother and that of the father's younger brother. Once the voice of an aunt, and once that of a deceased mother, was reported.

6 Initially the handwriting of the Kiyang-yang healers consisted of half-open O's resembling the signs of an ophthalmometrist (de Jong 1987). Later the handwriting became more elegant and had a resemblance to Arabic (Callewaert 2000), although the Kiyang-yang claimed not to have been in contact with the Koran. Also, the 'speaking in tongues,' the glossolalia or neoglossia, sounded like formless speech components, there being no question of a (new) language (de Jong 1987).

7 Later on she became more exigent and required the following of her instructions. She did not succeed in this regard, probably because the Balanta do not recognize a central authority (neither in colonial time nor after independence) and therefore are often described as being fundamentally anarchistic. The latter to some extent explains the repressive reaction of the party and state authorities against the Kiyang-yang.
} 
codes, according to her followers the norms transmitted via the ancestors' voices were absolutely binding. Whoever did not adhere to these instructions was immediately chastised by god and lost control over her body, which jerked upward in all directions and was then hurled against the ground. Or she was made to run at great speed against a wall or a tree so that blood flowed from her wounds. ${ }^{8}$

The followers initially expressed their individual plight, which often focused on barrenness or losing their children. When they started to hear voices and receive commandments from Nhaala, however, these voices pointed to problems of a collective rather than an individual level. During the fieldwork, it became clear that the number of commandments varied per individual, as did the order in which god passed on his directives. A list of commandments and prohibitions follows below, in order of frequency as mentioned by the interviewees wherever possible. All the directives deviate radically from what is considered normal or acceptable among the Balanta.

These are the 14 commandments of Nhaala.

I. All ancestors' spirits and shrines must be abolished. ${ }^{9}$

II. All practices connected with witchcraft must be stopped.

III. Slaughtering all the cows of a deceased person during the mourning ceremony should stop. Only one cow shall henceforth be laid on the ground with its legs tied together, after which its throat is cut and the meat is divided among those present including women and children. ${ }^{10}$ The meat that is distributed during the mourning ceremony must be consumed at once, and all must weep for the deceased.

IV. The slit drums must remain silent during mourning ceremonies and people should cry for the deceased.

V. There is to be no more stealing; people must grow rich with their own labor.

VI. There must be no adultery and no eloping.

VII. No red clothes may be worn, or red foods eaten. ${ }^{11}$

VIII. Children must be sent to school.

IX. The people must not speak evil but must speak the truth at all times.

$\mathrm{X}$. Each person must choose his or her own marriage partner.

\footnotetext{
${ }^{8}$ Some respondents explained that the elderly had compassion for the Kiyang-yang because of these wounds and therefore did not oppose the movement.

9 With the exception of the shrine, the iran, at the entrance of the compound.

${ }^{10}$ This commandment is also related to witchcraft because when the throat of a cow is slit and she still moves, the person who stands near the place where the cow falls on the earth is normally accused of witchcraft. Instead of taking the cow meat home, it should be eaten at the mourning site, called semola (alm in Portuguese and Crioulo), a word with an Islamic connotation. Balanta mourning rituals often involve hundreds of family members. The men not only pass out a couple of times because of excessive alcohol use but also get involved in fighting over the symbolically and hierarchically significant distribution of the meat of their totem animal, which often results in wounded or dead people, contributing to the Balanta image as savage and primitive people. As we will see further on, many of the commandments of Nhaala address this perceived backwardness.

11 Because of its connotation of blood and slaughtering animals for the ancestors. This also applies to chabeu, red palm oil.
} 
XI. In case of death, no diviner or oracles, including the djongagu, ${ }^{12}$ should be consulted to discover who is to blame for the death.

XII. No river crabs may be eaten.

XIII. Indicate witches. This commandment deserves special mention because it can cause considerable conflict between Kiyang-yangs and others. A voice can announce when someone is a witch, and sometimes gives the order to inform the witch concerned. An accusation of witchcraft is regarded as a capital crime within the traditional culture; it is punished by the government, and the one who accuses is rejected by Ntombikte. However, if a Kiyangyang ignores the order from one of her voices that she must make an accusation of witchcraft, the aforementioned chastising mechanism of god can come into effect so that she eventually carries out the order.

XIV. Like the men, women have to till the land and grow new crops, vegetables and fruits.

Over the years, some of the commandments waned, such as eating river crabs, which is regarded as a symbol of poverty, whereas others were emphasized more and also received more priority in Ntombikte's own compound, such as growing crops.

\section{Repression and Acceptance}

The sudden and spectacular rise of Kiyang-yang aroused the government's suspicion and resulted in systematic repression. The conflict between the government and Kiyang-yang overlapped with alleged ethnic tensions. In November 1985, about 150 Balanta were imprisoned and accused of conspiring for a coup d'état. Soon afterward, the same fate befell Vice President Paulo Correia, appointed next to the Papel President Vieira, and the dismissed Attorney General Viriato Pam. Both Balanta men allegedly tried to sow unrest among their people with the assistance of the Kiyang-yang. Many of the imprisoned Balanta were tortured and finally executed, among whom numbered Correia and Pam. In that period, Ntombikte was imprisoned in a military camp near the capital and later exiled to the north for more than one year. In the meantime, the movement was spreading in the south, the central region and, to a lesser extent, the north of the country. ${ }^{13}$

In 1987, political change relieved the harsh repression of the previous years. Between 1987 and 1992, the movement showed a tendency toward institutionalization. Grosso modo Kiyang-yang lost its spontaneous, trancelike, violent, confrontational character. Most of the Kiyang-yangs changed their lifestyle in accordance with the orders of Nhaala but still consulted their ancestral voices from time to time on daily matters. In compounds where the Kiyang-yangs had thrown out the ancestor shrines, people no longer drank alcohol, ate pork, practiced the

\footnotetext{
12 The practice of exposing or carrying around of a deceased's body in order to search for the death's cause. The word djongagu refers to the bier that is used for this purpose.

13 Generally, one specialized Kyiang-yang healer could be found in every one to four Balanta villages, with a total average number of about 700 inhabitants.
} 
djongagu when someone died, or played the slit drums; nor did they kill all their cows at the mourning ceremony.

Most Kiyang-yangs stopped working as healers, but a few dozen seemed so gifted that they had a regular clientele, even from other ethnic groups. Their healing practices aimed mainly at illnesses concerning female fertility and childhood diseases. In addition, these Kiyang-yang-healers dealt with witchcraft practices, whereas active witchcraft accusations by Kiyang-yang had become rare. Most of them were able to 'write' (see footnote 7, above). Except for a few cases, Kiyangyang membership had hardly crossed ethnic boundaries, and the members of other ethnic groups who had been called by Nhaala often had a Balanta mother. The relatively small number of gifted or specialized Kiyang-yang healers were acting more and more as 'priests.' Besides their well-visited healing practices, they were developing rituals in which considerable numbers-especially women-joined in mass prayer, resembling rudimentary Islamic or Christian services. The next case illustrates this (van der Drift 1992). ${ }^{14}$

On the first of January 1992, a Kiyang-yang New Year's ceremony is taking place in a Balanta village in southern Guinea Bissau. A group of about 150 people is running through the extended forest in which the village is situated. Now and then, the group holds before a traditional ancestor shrine. The spiritual leader, dressed in a long white gown, wearing a self-written book with Arab-like handwriting, and a Muslim 'rosary' kneels down in a Muslim prayer position facing the animist shrine. He then launches a hymn called "Gloria," addressing himself to Nhaala. The followers are mostly women, apart from a handful of young men. Some among them incidentally get into trance, but on the whole the procession is orderly. Later that day, on the central yard in the leader's compound, an enormous amount of rice and chicken is prepared, brought together by the women (cf. Callewaert 2000). In the backyard a group of male village elders is received with several liters of local distillate. Some of the elders appear to support the Kiyang-yang leader, ostensibly demonstrating their authority. Before the food is distributed, the Kiyang-yang leader addresses himself once again to Nhaala, asking for his blessings. He expresses the wish that people stop using occult powers to reach their goals and, instead, work hard for their own benefit.

Kiyang-yang healers still were in contact with Ntombikte. Her directives, which often were not followed up, had become more concrete in an economic sense. She was placing more emphasis on hard work, the promotion of certain crops (notably fruit trees) and the rehabilitation of the colonial agricultural system, the plantation (ponta). Subsequently, until today, in line with the decentralized Balanta sociopolitical organization, Kiyang-yang had developed into a regional institution without a hierarchical organization. During our last visit in 2008, Ntombikte expressed her disappointment about this development. She told us that many

\footnotetext{
${ }^{14}$ We owe the following paragraph to Roy van der Drift, who did his ethnographic fieldwork in the southern Balanta area of Enchudé.
} 
Kiyang-yang followed their own interpretations, and she said, "They do not want to listen to me" (ie ka miestie obing).

\section{Discussion}

It is exceptional for scholars to get an opportunity to study the emergence of a new idiom of distress from the very moment of its inception and to follow its development over a 25-year period. This discussion focuses on a few elements that, in our view, are important to illustrate our interpretation of this idiom of distress.

First, an individual expression of distress can only develop into an idiom of distress if its language can be understood and appropriated by others. In the case of Kiyang-yang, it would be a misunderstanding to perceive its origin as an idiosyncratic phenomenon. The new idiom derived elements from previous movements of the Balanta ethnic group in times of crisis. On the one hand, Kiyang-yang resonated with waves of witchcraft accusations and witch cleansing, such as occurred during the French 'pacification' of the south of Senegal (Roche 1976). On the other hand, it resonated with an episode during the Liberation War against the Portuguese (1962-1974). After 2 years of fighting, resulting in widespread traumatization of the population, two-thirds of the Guinean territory had been liberated from Portuguese domination. The liberation movement PAIGC held its first congress in 1964 in Cassaca, in the liberated Balanta areas in the south. At that time, Ntombikte, the firstborn to her parents and by then a 15-year-old girl, lived in a nearby village. At this party congress, Balanta commanders were punished, having been accused of hunting and killing alleged witches in close collaboration with women's Fyere Yaabte groups. ${ }^{15}$ The Fyere Yaabte is a healing cult of women who-up until today-come together in times of disaster and, notably, when there is an epidemic with high child mortality, such as measles, diarrhea or cholera. Several elements of Fyere Yaabte are articulated in the Kiyangyang: a group of women under the leadership of a head woman, divination, sacrifice, immersion rituals, curing — of barrenness, for example-and the most important healing activity of both cults, the fighting of witches and the fetching or retrieving of stolen souls (de Jong 1987). Unlike the Kiyang-yang, the Fyere Yaabte is not perceived as subversive because the women do not move out from the virilocal compound and are even esteemed by the elders in times of witchcraft

\footnotetext{
15 One of these groups was led by a Balanta woman, Kubai Na N'Satma, who had gathered around her a number of women who traveled from one Balanta village to the next pointing out 'witches' and accusing them of causing the deaths of villagers who had died in the war, e.g., as a consequence of the Portuguese bombings. These witches-several hundreds of them-were put under the charge of the party commanders and were subsequently tortured and shot or burned at the stake. At the aforementioned congress, the commanders were required to justify their actions and about a dozen of them were sentenced to death. Kubai, too, stood trial. The liberation movement had restored order, realizing that it had only just survived this so-called 'reverting to obscurantism.' As happened with other witch-cleansing cults such as the Fipa of Tanzania and the Tiv-cults or the Atinga in Yoruba-land, the Kiyang-yang movement manifests the paradox of abolishing witchcraft by means of witchcraft accusations (de Jong 1987).
} 
epidemics - the emic interpretation of what, from an etic view, is regarded as a disease epidemic. Unlike the Kiyang-yang, the Fyere Yaabte does not oppose the basic Balanta structure, with its ascription of authority to lineage elders by birth rank and age (cf. Handem 1986). The Kiyang-yang receive their authority by a dissociative trance during their 'calling' or 'seizure,' perceived as Nhaala's intervention and mediated by the voices of ancestor spirits. In contrast with the Fyere Yaabte, the Kiyang-yang replaced the spirit cult rituals of libations and sacrificial meals with community charity meals ${ }^{16}$ (Callewaert 2000, p. 211).

In short, when Ntombikte chose to express her suffering through Kiyang-yang, she articulated in a sophisticated way a movement that addressed both individual and collective suffering caused by epidemics that are locally interpreted as periods of increased witchcraft activities. Building on the Fyere Yaabte cult enabled Ntombikte's environment to understand and accept what she was doing. However, Ntombikte carried the problem of barrenness and child mortality to a supraindividual level by addressing a perceived lack of social justice and by dealing with traumatic stress caused by the liberation war. The orders against witchcraft, ancestor spirits and animal sacrifice were ascribed to the Balanta supreme being. This made her preaching relevant for the whole ethnic group, thus enabling the expression of collective traumatic stress among the Balanta through the idiom of distress. On an individual and family level, the idiom addressed the sorrow, the hate, the suspicion against and the self-blame of women-including Ntombikte herself-who suffered from barrenness and infant death. Without an ancestor cult, a barren woman does not need to worry about her reincarnation in a (grand)child she cannot have. Additionally, without witchcraft, a woman or her family does not suffer from the possible stigma of having killed her own child. A woman who suffers the loss of her children can hardly express and process her grief and feelings of loss when her environment or her 'inner voice' attributes her suffering to witchcraft, or sacrificing the vital force and thus the life of her child for the sake of her own material benefit. Moreover, a woman who suffers from infertility is morally blamed for the existential void in which she finds herself due to the inability of her soul to reincarnate in her offspring. The Kiyang-yang idiom of distress became the vehicle of an attempt to radically eradicate these two sources of suffering by abolishing witchcraft and by abolishing ancestor belief. On another and higher system level, that is, the level of the ethnic group, the idiom addressed the poverty, injustice and marginalization by the failing state, as well as the backwardness of the ethnic group and the lack of hope. By following Nhaala and by abolishing witchcraft, the new movement hoped to guide the Balanta into the modern world. They would be able to send their children to school and participate in a market economy without fear of envy and witchcraft, and without having to sacrifice their surpluses to the ancestor shrines or during mourning rituals.

In other words, through the idiom of Kiyang-yang, marginal women and, later, men were able to relate their individual suffering in a metaphorical way to suffering

\footnotetext{
${ }^{16}$ Called semola (alm) in the lingua franca Creolo and in Portuguese, and related to the Islamic habit of giving alms.
} 
on a collective level. Their idiom of distress provided an embodied language for communicating individual traumatic stress as well as a variety of stressors that caused widespread suffering among the Balanta. Through this legitimate idiom, they could express their suffering in an externalizing way by pointing to structural evils in Balanta society.

Second, as we described at the beginning of this paper, we regard an idiom of distress as a shared but embodied symbolic language for the expression of suffering that, due to its metaphorical character, principally links suffering on different levels - in this case, the level of individual followers and that of the Balanta as an ethnic group. In addition, it enables and legitimizes the expression of social suffering that cannot be otherwise expressed and therefore is always related to structural problems or tensions inherent to the society. For the very reason of being ambiguous and subject to multiple interpretations, such an idiom of distress carries the potential for becoming a vehicle for the expression of a range of social and political sentiments. Thus the political threat: such an idiom evolves into a political movement, aiming to alter the structural conditions that underlie this suffering. This is what the political leaders observed: an innocent healing cult for young barren women gradually shifted to a collective idiom that affected the pillars of social life of the Balanta. Moreover, it affected the relation of this majority ethnic group with the state, where it was minimally represented despite its acknowledged fundamental role in the liberation struggle. ${ }^{17}$

We argue that an idiom of distress may only continue to exist if it does not make explicit or effectively eliminate the social suffering that it articulates. Once the suffering can be directly expressed and solved both socially and politically, there is no longer a need for a metaphorical mode of expression. The idiom of distress will then lose its raison d'être and evaporate or dissipate. In the case of Kiyang-yang, several factors helped to prevent the development of the idiom of distress into a political movement. On one hand, there were several factors inherent to the movement itself. It abolished witchcraft by silently or publicly indicating witches, thus implicitly perpetuating the witchcraft belief as such (cf. Geschiere 2000). Individual and private motives of followers making accusations of witchcraft as forced on them by Nhaala could not be contained by the preaching of Ntombikte. She instructed her followers to send a witch away without public exposure. However, the followers were obliged to follow the instructions of Nhaala through their ancestral voices, and they severely chastised them if they did not indicate a witch. Apparently, the personal motive of the follower in relation to a perceived witch had priority over the instructions of Ntombikte. The follower could obey her supreme being Nhaala, thus disobeying Ntombikte, or listen to Ntombikte and be chastised by Nhaala. From the start, there was a contradiction between Ntombikte and her followers related to the abolishment of the ancestors. Whereas Ntombikte wanted to abolish the ancestors, and many Kiyang-yang paid lip service to this rule, in practice the ancestors continued to be the elected vehicles of Nhaala's

\footnotetext{
17 The state had hardly compensated the Balanta for their involvement in the struggle and given more support to the Muslim ethic groups that were regarded as collaborators with the Portuguese. The Balanta regarded this as an act of disloyalty.
} 
commandments. By abandoning the ancestors, the Kiyang-yang followers would cut off the only communication channel with their own supreme being.

On the other hand, there were state-related factors in the containment of the movement. In our opinion, it is fundamental that repression by the state helped the continuation of Kiyang-yang as a shared idiom of distress. To understand that repression, we have to make a short historical excursion into the ideological roots of socialist liberation movements in Africa. The previously mentioned head of the liberation movement PAIGC, Amilcar Cabral, often claimed to address and abolish the widely spread obscurantismo - a derogatory Portuguese word for magic beliefs-of his guerrilla fighters. As in Angola and Mozambique, these fighters, with very few exceptions, did not receive formal education during the Portuguese regime. In Guinea Bissau, the (ex-)fighters were and are deeply convinced, even today, that magic and witchcraft determine life, wealth and death. ${ }^{18}$ Although the liberation movement had formally abolished witchcraft and sorcery, during the many years that one of us (J.d.J.) had friends among the Guinean leaders, practiced psychotherapy with them or did ethnographic fieldwork among healers, it became clear that in the majority of cases the abandonment of magic thinking was only lip service to the party ideology. By formally abolishing witchcraft, Kiyang-yang exposed the bad conscience of a large part of the 'liberated' elite that was in charge of the single political party at that time. Moreover, as in most African countries, accessing high spiritual forces, including witchcraft and sorcery, is a prerequisite for secular power that the Guinean leaders did not want to abrogate. ${ }^{19}$ Another noteworthy characteristic of the Kiyang-yang was that it addressed the myth of social equity that prevailed after the country's independence. Both state officials and development organizations embraced the party ideology, first articulated by Amilcar Cabral, that the Balanta were noble, hard-working and egalitarian savages, living in harmonious communities (cf. Cabral 1975). Postwar politicians and policymakers acted as if the Balanta were the same people as they (allegedly) had been before or during the war. Consequently, Kiyang-yang came as a shock, after the Balanta had suffered from war stress and precarious living conditions for years, both in the deteriorating national economic situation since independence and in the repressive authority of their village elders (cf. van der Drift 1992). A majority of Nhaala's commandments addressed the backwardness and the poverty of the Balanta and

\footnotetext{
18 For example, President Nino Vieira, in his time as a commander in the liberation movement, was said to be protected by a magical bullet treatment that exists all over the African continent. When he was in battle, Amilcar Cabral sent several young recruits with him to prevent comrade "Nino" from standing up and running against a rain of bullets. During and after the liberation struggle, almost nobody questioned that story. Nino Vieira was from the minority ethnic group the Papel, who live around the capital. Due to his charisma (and the stories about his invincibility), he was accepted by the Balanta as the president. The minority-origin of the president and several other leaders also clarifies some of the fears of the leaders surrounding the Kiyang-yang and the accusations and executions of some of the alleged Balanta leaders behind the movement.

19 Obviously, a politician or party member may not believe or may claim not to believe in these evil forces, in which case a family member may fulfill the ceremony or do the sacrifice to neutralize the evil, ward off the danger or placate the ancestors. Mozambique realized the tension between the Frelimo party ideology and the local beliefs, and its Ministry of Health invited the first author to address the issue of healers in 1991 (Jurg et al. 1991).
} 
therefore exposed the equality myth of the party and the state. The commandments also relieved the burden of traumatic stress by restoring self-esteem and selfconfidence of the Balanta, by providing a meaning to their decades of suffering and by offering hope of a better future. The Kiyang-yang made an ouverture that paralleled or even replaced the intentions of the party and the government: diversification of agricultural production, commercialization of surpluses, integration of a subsistence economy in the monetary economy, women's participation and the abolition of witchcraft, enabling people to become wealthy without raising suspicion (de Jong 1987). Therefore, a seemingly innocent movement initiated by a few illiterate women addressed crucial shortcomings of post-liberation-struggle politics. Interesting in this regard is that the state justified its repression against the Kiyang-yang by referring to witchcraft accusations in the liberated areas in the early sixties. ${ }^{20}$ The potential threat of the movement was immediately sensed by the government and the president. One move was to order the first author to treat the Kiyang-yang as psychiatric cases, which he deferred. This move was in line with the abuse of psychiatry in Soviet-backed Marxist regimes such as Guinea Bissau. As we have seen, other more outright forms of repression, such as imprisonment or execution, or, in Ntombikte's case, exile, were more successful. It prevented a major political uprising of the Balanta. ${ }^{21}$ In her temporary exile, Ntombikte lost control over her followers. She was not able to transform the idiom of distress into a political movement under the unitary leadership of Nhaala with her as the central prophet, as happened with Lakwena and the Lord's Resistance Army in Uganda (Allen 1991) and some of the cults of (counter-)violence in Mozambique (Vines 1991; Wilson 1992). By allowing new Kiyang-yang leaders, especially young men, to follow the voices of their ancestors, Ntombikte facilitated the movement to disperse to the north and to create a heterogeneous and decentralized movement (cf. Callewaert 2000). In our opinion, this fragmentation has contributed to the continuation of the idiom of distress until today.

One may ask to what extent Kiyang-yang as an idiom of distress fits the description of phenomena that Lewis, in his famous book Ecstatic Religion (2003), described under the denominator of peripheral possession. In some way, this question is rhetorical because the original conceptualization of idioms of distress by Nichter that we have built on was inspired by the work of Lewis and others who tried to focus on the sociopolitical contexts in which religious phenomena occurred, rather than on psychological processes intrinsic to certain individuals (e.g., trance, religious ecstasy). In line with older anthropological theories about symbolic protest (e.g., rituals of reversion [Gluckman 1954]), Lewis (2003) argued that peripheral

\footnotetext{
${ }^{20}$ A hypothesis formulated earlier (de Jong 1987:97) still has to be tested, i.e., that a similar possession movement at the beginning of the liberation struggle rapidly spread the party ideology throughout Balanta territory, another explanation of the fear of the country's leadership.

21 On the evening when the first author received a phone call from President Nino Vieira, via the Vice Minister of Health Dr. Paulo Medina, to attend to the problem, J.d.J. gathered with Ntombikte and a group of Kiyang-yang. This first meeting took place in the palace of the governor of the region, Paulo Correia, who was as surprised by their behavior as was the first author. Nevertheless, it was Paulo Correia who was accused of staging the movement as an uprising of the Balanta against the state and sentenced to death in 1985 .
} 
possession provides women and other underprivileged groups with a vehicle for expressing their complaints in a legitimate way, thereby offering them protection from the extremes of abuse and suffering inherent to their marginal and subordinate social position-without, however, changing the basic social and political structures that were fundamental to this suffering. This sociological understanding of the communication of distress in the context of sociocultural constraints against and opportunities for expression is also at the core of Nichter's (1981) definition of idiom of distress. It is also at the core of our own more restricted definition of an idiom of distress as a legitimate language for suffering that cannot be otherwise expressed in the local social-cultural-political context due to its inherent threat to dominant values and structures.

As a heuristic tool, the concept of idiom of distress thus helps us to focus on the sociopolitical roots of the suffering expressed by those that make use of the Kiyangyang idiom. It helps to focus on what is at stake in social suffering (Kleinman and Kleinman 1991) but cannot be fully resolved because it is related to the fundamental values the idiom supports (e.g., a woman who loses her child is either bewitched or a witch).

In Kiyang-yang, it is clear that the original sufferer, Ntombikte, did aim at a radical solution for her suffering, however. This does not contradict our interpretation, in line with Lewis' conceptualization of peripheral possession, but rather illustrates his argument. According to Lewis, peripheral possession has three dimensions: (a) the possessed themselves are socially marginalized or downtrodden; (b) the affliction they exhibit is peripheral in that it is not linked with the transgression of dominant norms and values, that is, the sufferers are not blamed for their suffering; and (c) the spirits themselves are marginal, often external to the societies of their victims (Lewis 2003, p. 27; cf. Reis 1993). The last two characteristics do not apply to Ntombikte's interpretation of Kiyang-yang, for the voice to whom she ascribed her inspiration was that of the paramount Balanta God, and her exegesis of the commandments she received pointed at evils the Balanta themselves were responsible for. In terms of Lewis's conceptualization of peripheral possession (cults) and central possession (religions) (28), Ntombikte aspired to develop Kiyang-yang into a central religion with her as paramount medium of the Balanta as an ethnic group. The processes of decentralization, diversification and repression described above allowed Kiyang-yang to continue among her followers as peripheral possession. We would like to mention here that what is considered peripheral and what central is also in the eye of the beholder. From the viewpoint of the newly established Marxist state of Guinea Bissau, which had to deal with widespread war traumatization and high expectations of reward and retribution, the voice of the paramount Balanta god was fundamentally peripheral to the state's aspirations of becoming one nonethnic nonreligious nation.

Third, and finally, we want to return to the multileveled manifestation and multiple interpretability that are characteristic of an idiom of distress, a trait it shares with any symbolic language (Turner 1967). We argue that it is exactly the characteristic vagueness that allows the genesis of a shared idiom of distress from an original individual expression of distress. Above, we mentioned that an individual expression of distress can only develop into a legitimate idiom of distress if its 
language can be understood and appropriated by others. Elaborating on this, we argue that for this to happen, there has to be some resonance at the level of the symbolic language (e.g., behavior recognizable as spirit possession, an exegesis in terms of culturally appropriate metaphors) as well as at the level of what it aims to communicate (e.g., the psychosocial suffering such as despair resulting from infertility or child death). It is the metaphorical dimension of an idiom of distress that allows for resonance on different levels of experience. As we have shown in the case of Kiyang-yang, the idiom allowed for a simultaneous embodied language for individual suffering and trauma and the suffering of groups of marginalized women, as well as the collective traumatic experiences of the Balanta. On the basis of our data, we argue that this linkage of different levels is not just a symbolic construction via the idiom as originally described by Lévi Strauss (1958; cf. Reis 1996). It also depends on real-life interrelated stressors playing on different levels. For example, infertility and child death are caused as much by individual conditions as by structural shortcomings, such as the postwar poverty and the marginalization of the Balanta as well as the deterioration and unavailability of health care (cf. Massé 2007). Another real-life connection takes place on the individual level of experience: a Kiyang-yang suffers simultaneously from being barren and being marginalized as a Balanta. All these factors elicit culturally mediated, contingent emotions such as despair and hopelessness. Defeat by infertility is therefore fundamentally related to defeat as a Balanta in this particular sociohistorical and cultural context (cf. Nichter 2008).

It is clear that the linkage of different levels through the aforementioned symbolic, causal and personal dimensions can only be subsumed under loose denominators, e.g., a social term such as 'marginalization' and 'peripherality' or a psychological term such as 'despair' or 'hopelessness.' These vague denominators enable an idiom to be generalized into a language that individuals and groups can embrace for a range of related reasons. Therefore, we strongly agree with Ensink and Robertson (1996, p. 162), who argue that cultural idioms of distress are not to be understood as discrete diagnostic categories. Additionally, we oppose the trend of recent textbooks that easily exchange culture-bound syndromes for idioms of distress or vice versa. Following Nichter, we therefore also oppose attempts by anthropologists and psychiatrists to translate an idiom of distress to a monodimensional 'psychotrauma' that, once translated, can be addressed or cured.

When, in 2008, we visited Ntombikte in her compound near Bedanda-hours away from any sign of 'modern' civilization, sitting on the veranda of one of her modest mud houses painted with white figures that Nhaala has shown her-she was in a slightly desperate and pensive mood. The roots of evil for neither women nor men had disappeared, her followers did not like to follow her instructions, the state was still capricious and failing and poverty was worse then ever before. She asked us where to go with the Kiyang-yang, but in view of all the structural violence surrounding her, we were unable to give an answer.

Open Access This article is distributed under the terms of the Creative Commons Attribution Noncommercial License which permits any noncommercial use, distribution, and reproduction in any medium, provided the original author(s) and source are credited. 


\section{References}

Allen, T.

1991 Understanding Alice: Uganda's Holy Spirit Movement in Context. Africa 61(3): 370-400.

Cabral, A.

1975 Unité et lutte I-II. Paris: Maspéro.

Callewaert, I.

2000 The Birth of Religion Among the Balanta of Guinea-Bissau. Lund: Studies in African and Asian Studies.

Davis, D.L., and L.M. Joakimsen

1997 Nerves as Status and Nerves as Stigma: Idioms of Distress and Social Action in Newfoundland and Northern Norway. Qualitative Health Research 7(3): 370-390.

de Jong, J.T.V.M.

1987 A Descent into African Psychiatry. Amsterdam: Royal Tropical Institute.

2007 Traumascape: An Ecological-Cultural-Historical Model for Extreme Stress. In Textbook of Cultural Psychiatry. D. Bhugra and K. Bhui, eds., pp. 347-364. Cambridge: Cambridge University Press.

2010 A Public Health Framework to Translate Risk Factors Related to Political Violence and War into Multilevel Preventive Interventions. Social Science and Medicine 70: 71-79.

de Jong, J.T.V.M., and R. Buijtenhuijs

1979 Guinea Bissau, a Liberation Movement to Power. Wageningen: De Uitbuyt.

Einarsdóttir, J.

2004 Tired of Weeping. Mother Love, Child Death, and Poverty in Guinea Bissau 2nd Edition. Madison: University of Wisconsin Press.

Ensink, K., and B. Robertson

1996 Indigenous Categories of Distress and Dysfunction in South African Xhosa Children and Adolescents as Described by Indigenous Healers. Transcultural Psychiatry 33(2): 137-172.

Furst, L.R.

2003 Idioms of Distress. Psychosomatic Disorders in Medical and Imaginative Literature New York: State University of New York Press.

Geschiere, P.

1998 Globalization and the Power of Indeterminate Meaning: Witchcraft and Spirit Cults in Africa and East Asia. Development and Change 29: 811-837.

2000 The Modernity of Witchcraft. Charlottesville: University of Virginia Press.

Gluckman, M.

1954 Rituals of Rebellion in South-East Africa. Manchester, UK: Manchester University Press.

Gustafson, P., V.F. Gomes, C.S. Vieira, H. Jensen, R. Seng, R. Norberg, B. Samb, A. Nauclér, and P. Aaby

2001 Tuberculosis Mortality During a Civil War in Guinea-Bissau. JAMA 286: 599-603.

Handem, D.L.

1986 Nature et fonctionnement du pouvoir chez les Balanta Brassa. Bissau: INEP.

Hollan, D.

2004 Self Systems, Cultural Idioms of Distress, and the Psycho-bodily Consequences of Childhood Suffering. Transcultural Psychiatry 41(1): 62-79.

Jurg, A., J.T. de Jong, T. Tomas, J. Marrato, M. Wilisone, and G. Kirchner

1991 Fornecedores e utentes de cuidados de saúde, modernos ou tradicionais, em Maputo, Mozambique. Maputo: GEMT.

Kirmayer, L.J.

1989 Cultural Variations in the Response to Psychiatric Disorders and Emotional Distress. Social Science and Medicine 29(3): 327-339.

Kleinman, A., and J. Kleinman

1991 Suffering and Its Professional Transformation. Toward an Ethnography of Interpersonal Experience. Culture, Medicine and Psychiatry 15: 275-301.

Lévi-Strauss, C.

1958 Structural Anthropology. New York: Doubleday.

Lewis, I.M.

2003 Ecstatic Religion. 3rd Edition. London: Routledge. 
Marwick, M.

1950 Another Modern Anti-Witchcraft Movement in East Central Africa. Africa 20(2): 100-112.

Massé, R.

2007 Between Structural Violence and Idioms of Distress: The Case of Social Suffering in the French Nichter, M.

Caribbean. Anthropology in Action 14(3): 6-17.

1981 Idioms of Distress: Alternatives in the Expression of Psychosocial Distress. A Case Study from South India. Culture, Medicine, and Psychiatry 5: 379-408.

2008 Coming to Our Senses: Appreciating the Sensorial in Medical Anthropology. Transcultural Psychiatry 45(2): 163-197.

Ranger, $\mathrm{T}$.

1986 Religious Movements and Politics in Sub-Saharan Africa. African Studies Review 29(2): 1-69.

Reis, R.

1993 Oog in oog met het kwaad: vernieuwing in de traditionele diagnostiek in Swaziland [Eye to Eye with Evil: Innovation in Traditional Diagnostics in Swaziland]. Medische Antropologie 5(2): 255-274.

1996 Douglas en het heilige onreine. Over de geneeskracht van sjamanen en clowns. [Douglas and Holy Impurity. On the Healing Power of Shamans and Clowns]. Focaal 28: 29-37.

2009 Children Confronting Conflict: From Child Idioms of Distress to Social Navigation. In Presented at Medical Anthropology at the Intersections: Celebrating 50 Years of Interdisciplinarity, Yale University, September 24-27.

Richards, A.

1935 A Modern Movement of Witch-Finders. Africa 8(4): 448-461.

Roche, C.

1976 Conquêts et résistance des peuples de Casamance (1850-1920). Dakar- Abidjan: Les nouvelles éditions Africaines.

Sargent, C.

2003 Gender, Body, Meaning: Anthropological Perspectives on Self-Injury and BPD. Philosophy,

Turner, V.W. Psychiatry and Psychology 10(1): 25-27.

1967 The Forest of Symbols. Aspects of Ndembu Ritual Ithaca, NY: Cornell University Press.

van der Drift, $R$.

1992 Arbeid en alcohol. De dynamiek van de rijstverbouw en het gezag van de oudste bij de Balanta Brassa in Guinee Bissau Leiden: CNWS.

van Dijk, R., R. Reis, and M. Spierenburg, eds.

2000 The Quest for Fruition Through Ngoma; The Political Aspects of Healing in Southern Africa. London: James Currey/Ohio Press.

Vines, A.

1991 Renamo Terrorism in Mozambique. Bloomington: Indiana University Press.

Willis, R.G.

1968 Kamcape: An Anti-sorcery Movement in South-West Tanzania. Africa 38: 1-15.

Wilson, K.B.

1992 Cults of Violence and Counter-Violence in Mozambique. Journal of Southern African Studies 18: $531-582$ 